\title{
Kronik Böbrek Hastalığında Travma Sonrası Büyüme
}

\section{Post-Traumatic Growth in Chronic Kidney Disease}

\author{
Canan KÖMÜRCÜ ${ }^{1}$, Ayşe KUZU² \\ ${ }^{I}$ Uzman Hemşire, Ankara Pursaklar Devlet Hastanesi, Genel Yoğun Bakım Ünitesi. Ankara, Türkiye \\ ${ }^{2}$ Dr. Öğr. Üyesi, Zonguldak Bülent Ecevit Üniversitesi, Ahmet Erdoğan Sağllk Hizmetleri Meslek Yüksekokulu. \\ Zonguldak, Türkiye
}

Geliş Tarihi: 19 Ocak 2020

Kabul Tarihi: 30 Ocak 2020

İletişim / Correspondence:

Canan KÖMÜRCÜ

E-posta: canan.kmrc@yandex.com

\begin{abstract}
Chronic kidney disease is a, which is life-threatening, causing significant loss of workforce and various complications, affecting almost every age group. Chronic kidney disease also constitutes an important risk group for mental disorders. The process of accepting the disease and adapting to the treatment in terms of the patient; constantly being dependent on the machine, institution, health personnel and relatives, fear of death, dietary restriction, changes in work, family and social life, along with the level of stress and anxiety in the patient increases and causes a traumatic situation. While traumatic experiences negatively affect an individual's physical, social and mental health, on the other hand, the experience of trauma; can lead to important positive changes such as priorities, the meaning of life, improving relationships, perception of personal empowerment. Positive changes formed in the person after the trauma is defined as "perceived benefit" "stressrelated growth" or "post-traumatic growth". It is stated that posttraumatic growth in chronic diseases has a positive relationship between stress coping strategies, social support and perception of spirituality and mental health and posttraumatic growth in chronic diseases is effective in developing attitudes that can help the individual to cope with negative life events. In this study, it is aimed to investigate posttraumatic growth in patients undergoing chronic kidney disease treatment.
\end{abstract}

Keywords: Chronic Kidney Failure; Trauma; Posttraumatic Growth.

\section{Özet}

Kronik böbrek hastalığı yaşamı tehdit eden, önemli ölçüde iş gücü kaybına ve çeşitli komplikasyonlara yol açan, hemen her yaş grubunu etkileyen bir hastalıktır. Kronik böbrek hastalığı ruhsal bozukluklar açısından da önemli bir risk grubu oluşturmaktadır. Hasta açısından, hastalığı kabullenme ve tedaviye uyum sağlama süreci; sürekli makineye, kuruma, sağlık personeline ve yakınlarına bağımlı olmak, ölüm korkusu, diyet kısıtlaması, iş, aile ve sosyal yaşamındaki değişimler, hastada stres ve kaygı düzeyini artırarak travmatik bir duruma neden olmaktadır. Travmatik deneyimler bireyin fiziksel, sosyal ve ruhsal sağlığını olumsuz etkilerken diğer yandan, travma deneyimi; öncelikler, yaşamın anlamı, ilişkilerin iyileştirilmesi, kişisel güçlenme algısı gibi önemli olumlu değişikliklere yol açabilir. Travmanın ardından kişide oluşan olumlu değişimler "algılanan yarar", "strese bağlı büyüme" veya "travma sonrası büyüme" olarak tanımlanmaktadır. 
Kronik hastalıklarda travma sonrası büyümenin; stresle baş etme stratejileri, sosyal destek ve maneviyat algısı ile ruhsal sağlık arasında pozitif ilişki olduğu ve olumsuz yaşam olayları ile baş etmede bireye yardımcı olabilecek tutumları geliştirmede etkili olduğu belirtilmektedir. Bu çalışmada kronik böbrek hastalığı tedavisi gören hastalarda travma sonrası büyümenin incelenmesi amaçlanmaktadır.

Anahtar Kelime: Kronik Böbrek Hastalığı; Travma; Travma Sonrası Büyüme.

\section{GİRIŞ}

Kronik böbrek hastalığ 1 yaşamı tehdit eden, önemli ölçüde iş gücü kaybına ve çeşitli komplikasyonlara yol açan ve hemen her yaş grubunu etkileyen bir hastalıktır. Kronik böbrek hastalığının tedavisinde kullanılan diyaliz ise hastaların yaşam süresini uzatmakla birlikte yaşam kalitesini de önemli ölçüde etkilemektedir. Hemodiyaliz tedavisine alınan hastanın hayatında önemli değişiklikler meydana gelmekte ve hasta makineye, kuruma ve sağlık personeline bağımlı olabilmektedir. Ayrıca hastalarda baş etmesi güç ve ağrılı işlemler, diyet kısıtlamaları, ek fiziksel ve ruhsal hastalıkların varlığı gibi pek çok sorun yaşanabilmektedir. Yaşanılan bu psikososyal sorunlar hastaların yaşam kalitesini olumsuz yönde etkileyerek travmatik bir yaşantıya neden olurken (1-3) diğer taraftan travma yaşantısı her zaman olumsuz bir durum ve kayıplarla sonuçlanmayabilir. Bu nedenle her bir travmatik durumun hem olumlu hem de olumsuz etkilerinin ele alınması önemlidir (4). Travmanın ardından kişide oluşan olumlu değişimler "algılanan yarar", "strese bağlı büyüme" veya "travma sonrası büyüme" olarak tanımlanır (5). Travmatik olay birçok kişiyi etkilemektedir ancak sadece bazı kişilerde travmanın olumlu etkileri gerçekleşir. $\mathrm{Bu}$ kişilerin etkin baş etme stratejilerine, sosyal desteğe ve maneviyat algısına sahip oldukları belirtilmektedir (3-5). Hasta ve ailesiyle doğrudan etkileşim halinde olan ve travmatik süreçte hastalarına bütüncül bir yaklaşımla bakım veren hemşirelerin, hastalarının güçlü yanlarını destekleyerek travma sonrası büyümelerini sağlamak, karşılaşılabilecekleri zorlu yaşam olaylarıyla baş etmelerine yardımcı olan önemli bir etmendir. $\mathrm{Bu}$ özden hareketle derleme, kronik böbrek hastalığ 1 olan bireylerde travma sonrası büyüme ve destekleyici hemşirelik yaklaşımına ilișkin bilgileri literatür doğrultusunda açıklamak amacıyla oluşturulmuştur.

\section{Travmatik Bir Yaşantı Olarak Kronik Böbrek Hastalığı}

Kronik bir hastalık tanısı almak pek çok birey için tehdit edici bir durum olarak algılanmakta ve hastalığa bağlı oluşan değişimler bireyin uyum problemi ve psikolojik sorunlar yaşamasına yol açmaktadır. Her bireyin hastalığa verdiği tepki farklıdır. Hastalığa verilen tepkiler; bireysel özelliklere, hastalığın şiddetine, süresine, etkilediğ organ ve dokuya, hastanın ve sosyal çevresinin hastalığa yüklediği anlama, sosyal destek durumuna ve hastalık hakkında sahip olunan bilgiye göre değişiklik gösterir (6). Yapılan araştırmalarda diyaliz hastalarında en çok görülen uyum sorunlarının; "tedaviyi reddetme, diyet uyumsuzlukları ve hastalık inkarı" olduğu bildirilmiştir (5). İnkar, uyum güçlüğü yaşayan hastalarda en sık görülen savunma mekanizmalarındandır. $\mathrm{Bu}$ durum genellikle hastanın makineye bağlı olma, otonomisini kaybetme, hastalığın kronikleşmesi gibi nedenlerle yaşadığı kaygı, öfke ve umutsuzluk duygusuyla ilişkilidir. Hastaların hastalığını inkâr etmesi tedaviyi de reddetmesine neden olmaktadır (6).

Kronik böbrek hastalığı olan bireyler, yaşadıkları biyopsikososyal zorluklar nedeniyle fiziksel, sosyal ve ekonomik kayıplar yaşayabilmektedir. $\mathrm{Bu}$ kayılar hastalarda, çeşitli uyum bozukluklarına yol açabilir. Bu bozukluklar her hastaya göre değişmekle birlikte benzer ruhsal tepkiler şeklinde ortaya çıkar. Bireylerin kronik bir hastalığa yönelik ruhsal tepkileri genellikle yas, depresyon, kaygı inkâr, kızgınlık, yansıtma, 
patolojik bağımlılık, agresif direnç, regresyon ve suçluluk duygusu șeklinde olmaktadır (7). Bu duygusal durumlar, bireyin davranışlarına çevreye yönelik ilgisizlik, birçok şeyden aşırı korkma, bakım verenlere yönelik aşırı düzeyde bağımlılık ya da bağımsızlık, isyankârlık, kendilerine yasaklanan şeyleri yapma isteği, utangaçlık, yalnızlık ve sağlıklı insanlara karşı öfkelenme şeklinde yansıyabilir. Kronik böbrek hastaları da benzer sorunlarla birlikte sosyal çevreleriyle olan ilişkilerinde de zorluklar yaşayabilmektedir (1,7,8). Mutlu (2007) çalışmasında, kronik böbrek yetmezliğine sahip hastaların \%59,2'sinin arkadaş ve akrabalarıyla ilişkilerinin azaldığını, \%12,8'inin yaşamakta olduğu çevreyi değiştirmesi gerektiğini, \%1,7'sinin eş ve çocukları tarafindan terk edildiğini, \%38,5'inin ise diğer insanlardan beklentilerinin arttığını belirtmektedir (9). Ayrıca kronik böbrek yetmezliği olan hastalarda aile içi baş etmede yetersizlik, iş/okul dengesini sağlamada zorlanma, ekonomik zorluklar, sosyal dışlanma ve geri çekilme gibi sosyal işlevsellikle ilgili sorunlar yaşanabilmektedir (7). Zengin ve Yildırım (2017)'in hemodiyaliz hastaları ile yaptıkları araştırmada hastaların yaşadıkları psikososyal sorunlar; terk edilme, geçmişe duyulan özlem, sosyal destek ve arzu edilmeyen cinsel ilişkiye zorlanma olarak belirlenmiştir (10). Kronik böbrek yetmezliği yaşayan hastalar, hastalığın yarattığı fiziksel ve psikososyal sorunların etkisi nedeniyle ruhsal bozukluk yaşama konusunda toplumdaki diğer bireylere göre daha fazla risk altında olabilmektedir. Yavuz ve ark. (2012) yaptıkları bir çalışmada hemodiyaliz tedavisi alan hastalarda psikiyatrik morbiditenin genel popülasyona göre $\% 43$ oranında daha yaygın olduğunu belirlemişlerdir (11).

Hastalığın evresi, süresi, şiddeti ve psikososyal etmenler hastalarda depresyon, anksiyete, organik beyin hastalıkları, uyum ve davranış bozuklukları gibi birçok ruhsal sorunun oluşma sıklığını etkilemektedir. Yapılan araştırmalarda, kişinin sağlığının sürekli tehdit altında olması, hastane süreçlerinin sürekliliği, yaşanan fiziksel kayıplara bağlı olarak değişen roller, aile ve yakın çevrede yaşanan sorunlar nedeniyle hemodiyaliz hastalarında depresyonun sık görüldüğü bildirilmiştir $(8,10,12)$. Bununla birlikte anksi- yete bozuklukları kronik tıbbi hastalıklar ile güçlü bir ilişki içindedir; bedensel sağlık ve yaşam kalitesi arttıkça kaygı azalmakta, fiziksel yeti yitimi ile doğru orantılı biçimde artmaktadır (13). Birçok araştırma diyaliz hastalarında anksiyete düzeyinin yüksek olduğunu göstermiştir (1416). Özatalay (1990)'ı yaptığı çalışmada hemodiyaliz hastalarının yaşadığı anksiyetenin hastaların günlük yaşantısını, aile ve evlilik ilişkisini olumsuz etkilediği belirtilmektedir (15). $\mathrm{Bu}$ bağlamda ruh sağlığı açısından bakıldığında haftanın belirli gün ve saatlerinde sağlık kurumuna gitme ve diyaliz makinesine bağlanma durumunda kalan kronik böbrek yetmezliği hastaları için, bu durum bireyin bağımsızlığını tehdit eden, aile, iş ve sosyal yaşantısında çeşitli sorunlara neden olan ve yaşam kalitesini olumsuz etkileyen travmatik bir yaşantıdır (1).

\section{Kronik Böbrek Hastalığında Travma Sonrası Büyüme}

Travmanın ardından kişide oluşan olumlu değişimler "travma sonrası büyüme" olarak tanımlanmaktadır (17). Travmanın birey üzerindeki olumlu etkilerinin sistematik olarak incelenmesi 1990'l1 yılların ortalarından itibaren hız kazanmıştır (18). Travmatik yaşantılar sonrasında gerçekleşen travmatik büyüme bireylerin yaşamlarında olumlu değişimler sağlayarak, karşılaşılabilecekleri zorlu yaşam olaylarıyla baș etmelerine yardımcı olan önemli bir etmendir (19). Tedeschi ve Calhoun (2004) travma sonrası büyümenin bireylerde kendilik algısı, insan ilişkilerindeki değişim ve yaşam felsefesinde meydana gelen değişim şeklinde olumlu etkilerinin olduğunu belirtmektedir (17). Bireylerin kendilik algısındaki değişimi, kendine güven ve duygusal güçlenmeyi içermektedir (20). Kendilik algısı gelişen kișiler güçlü, kendine daha çok güvenen, biricikliğinin farkında olan, daha gelişmiş bir "ben"e sahip, daha açık, daha empatik, daha yaratıcı, daha olgun, daha insancıl, "özel” olduklarının farkında olma özelliklerine sahiptir (21). Travmatik bir yaşantı sonrası bireylerin kendilerini daha güçlü ve özgüvenli hissettikleri (17), kendilerini kurban yerine travmayı atlatmış biri olarak gördükleri ve kişilerin diğer zorlu yaşam olaylarıla baş edebilecek gücü kendilerinde daha çok buldukları belirtilmektedir (20). 
Literatürde travmatik büyüme konusunda yapılan çalışmalar incelendiğinde sıklıkla cinsel taciz mağdurları (20), HIV virüsü taşıyan kişiler (22), kanser hastaları (23), engelli çocuğa sahip aileler (24), askerler (12), kayıp yaşantısı olan bireyler, trafik kazası geçirenler (25), depremzede çocuklar (26), çocukluk çağında tacize uğramış çocuk ve ergenler (27), yerinden zorla sürülmüş kişiler (28) ile yapılmış çalışmalar olduğu görülmektedir. Travma sonrası büyümeye ilişkin kronik böbrek hastalığı olan bireylerle yapılan çalışmalara literatürde sık rastlanmamakla birlikte; Cui ve ark. (2017)'nın hemodiyaliz hatsalarında travma sonrası büyüme ile ilgili yaptıkları çalışmada hemodiyaliz hastalarında algılanan sosyal desteğin travma sonrası büyümeyi olumlu yönde etkilediği bulunmuştur (29). Sadeghour (2019)'un yaptığı çalışmada hemodiyaliz hatsalarında travma sonrası büyümede duygusal zekanın belirleyici rolünün olduğu belirlenmiştir (30). Kamran (2017)'ın böbrek nakli yapılan hastalarla yaptığ 1 çalışmada, yaşam kalitesi ve travma sonrası büyüme arasında pozitif yönde bir ilişki olduğu, travma sonrası büyümenin hastaların yaşam kalitesini olumlu anlamda etkilediği saptanmıştır (31). Ayrıca travma sonrası büyümenin kimlerde daha fazla görüldüğü ve gelişmesinin ne şekilde kolaylaştırılacağ 1 konusunda yapılan çalışmalarda sosyal destek, maneviyat algısı, olumlu stresle baş etme ve psikolojik dayanıklı11ğın travma sonrası büyümeyi etkilediği belirtilmektedir (4,29,32-36). Hemodiyaliz hastalarının algıladıkları sosyal destek seviyesi arttıkça hastaların yaşam memnuniyeti artmakta, bu duruma bağlı olarak depresyon görülme siklığı ve hastalığın yükü azalmaktadır (37). Hemodiyaliz hastalarıyla yapılan bir çalışmada da algılanan sosyal destek ve stresle başa çıkma tarzlarının travma sonrası büyümeyi etkileyen önemli değişkenler olduğu (32), diyaliz hastalarında zorlayıcı yaşam değişikliklerine neden olan tanı ve tedavi süreci için etkili baş etme becerilerini kullanmalarının önemli olduğu (38) belirlenmiştir. Mok ve Tam (2001)'ın yaptıkları çalışmada beş yıldan daha uzun süredir hemodiyaliz tedavisi gören hastaların problemlerini hem duygusal hem de problem odaklı baş etme yöntemleriyle çözmeyi öğrendikleri (39); Hiçdurmaz ve Öz (2009)'ün hemodiyaliz ve sürekli ayaktan periton diyalizi uygulanan hastalarla yaptığ en sık kullandığı stresle baş etme yönteminin "dine yönelme" olduğu (40); Özcan ve ark (2000)'nın yaptığı bir başka çalışmada ise yaşamı boyunca hemodiyaliz makinesine bağlı olan hastaların zamanla hastalığ kabullenme sürecinin kısaldığı ve daha etkili baş etme yöntemleri geliştirebildikleri saptanmıştır (41).

\section{Kronik Böbrek Hastalığında Travma Sonrası Büyüme ve Hemşirelik}

Travma yaşamış kişi ile çalışırken amaç: kişinin yaşamına devam edebilmesi, başka bir deyişle "bu olay yüzünden artık her şey bitti" konumundan "bu olay bana bir şeyler ögretti ve yaşamıma devam edebilirim" konumuna geçmesini sağlamaktır $(42,43)$. Bireyin kendisiyle ve diğer insanlarla barışması, geleceğe dair olumlu ve umutlu beklentilerin, hedeflerin oluşturulması önemlidir $(43,44)$. Bu durum biyopsikososyal bir yaklaşımla, travmatik bir yaşamı olan hasta ve ailesinin fiziksel, ruhsal, psikososyal ve spiritüel gereksinimlerine odaklanan hemşireler için de önemlidir. Özellikle kronik hastalığ1 olan bireylerde psikososyal bakıma odaklanan Konsültasyon Liyezon Psikiyatri hemşiresinin birincil amac1 fiziksel hastalığa sahip olan hastaların bütüncül sağlığını yükseltmek, psikiyatrik bozuklukları önlemek ve azaltmak, psikososyal uyuma yardım etmek, bireyin mevcut hastalığ 1 ile hastalığının yol açtığı yaşam zorluklarıyla baş edebilecek güce gelmesine, hastalık yaşantısından anlam çıkarabilmesine yardımcı olmaktır (42). Hemşireler bakım verdiği kronik böbrek hastalığı olan bireylerde travma sonrası büyümeyi geliştirmek için öncelikle hasta ve hasta yakınlarından bilgi toplamalı, hastayı yaşadığ sorunlarla ilgili konuşması için cesaretlendirmeli, hastanın duygularını kabul etmeli ve onaylamalıdır. Hastayı, yaşadıklarının normal tepkiler olduğunu anlaması için desteklemeli, tehditkar olmayan özel bir çevre sağlamalı ve eğer hasta isterse başka bir kişi de bu çevreye dahil edilmelidir (42). Bununla birlikte hemşire, travmatik bir deneyim olarak hastalık yaşantısının birey ve ailesi tarafindan nasıl algılandığını iyi değerlendirmelidir. Aynı tanıyı almış bireyler arasında bile olaya karşı gösterilen tepkiler birbirinden farklı olabilmektedir. Hasta birey ve ailesi için bu travmatik olayın anlamının ne olduğu ve mevcut durumun onları nasıl etkilediği 
belirlenmelidir. $\mathrm{Bu}$ süreçte varsa gerçekçi olmayan düşünce ve beklentiler değerlendirilmeli, durumu gerçekçi ve sağlıklı bir biçimde algılamaları sağlanmalıdır $(44,45)$. Hemşirenin önemli sorumluluklarından birisi de travmatik durum karşısında yalnızlık, yardımsızlık ve çaresizlik duyguları yaşayan hasta birey ve ailesi için mevcut destek kaynaklarını farkettirmektir. Hemşireler tarafından sağlanan bakım desteğinin yanı sıra hasta ve ailesine onları bu süreçte yalnız bırakmayarak destek veren ya da bir takım gereksinimlerinin karşılanmasında araçsal destek sağlayan kişilerin fark ettirilmesi var olan desteğin algılanmasında önemlidir (46). Travma sonrası tepkilerin çözümü, büyük bir oranda baş etme stratejilerinin etkili bir şekilde kullanılmasını gerektirir. Hemşire, hastanın geçmişte kullandığ 1 uyumlu ya da uyumsuz baş etme stratejilerinin yanı sira travmaya tepki olarak kullandığı baş etme stratejilerini ifade etmesi konusunda cesaretlendirmeli, bu stratejileri tanımlamalı, gelecek için alternatif uygun baş etme stratejileri geliştirmeli (nefes alma ve gevşeme egzersizleri gibi) ve hastaya uygun destek girişimlerini (kültürel değerler, inanç gibi) önermelidir (46-48).

Bu bağlamda kronik böbrek hastalığı olan birey ve ailesinin fiziksel, sosyal ve psikolojik tüm gereksinimlerini değerlendirerek sorunlarla baş etmesini ve travma sonrası büyümesini etkileyecek özellikleri belirlemek, olumlu baş etmelerini güçlendirmek, sosyal destek kaynaklarını fark etmelerini sağlamak, hastalık yaşantısı gibi travmaların büyüme ile sonuçlanmasını sağlamak etkin hemşirelik yaklaşımlarındandır $(43,44)$.

\section{SONUÇ VE ÖNERILER}

Kronik böbrek hastalığı tanısı ve diyaliz tedavisi almak, hasta ve ailesi için pek çok kısıtll11kları beraberinde getiren önemli bir yaşamsal travmadır. Hasta ve ailesinin yaşadığ 1 psikososyal sorunlar ve travmatik durumlarda yaşanılan psikososyal riskleri değerlendirme, etkili sorun çözme ve baş etme becerisi kazandırma, bireylerin güçlü yönlerini açığa çıkarma, yeni duruma uyum sağlama gibi travma sonrası büyümeyi kolaylaştıracak davranışları geliştirebilmek için klinik, eğitim, araştırma, yönetim gibi rolleri olan Konsültasyon Liyezon Psikiyatri hemşirelerinin kliniklerde aktif olarak rol almaları gereklidir. Kronik böbrek hastalığ büyümeyi sağlamak amacıyla; bakım veren klinik hemşirelere yönelik hasta ve ailesinin yaşadığ psikososyal sorunlar konusunda farkındalık oluşturmak, hemşireleri hasta ve ailesine yaklaşım konusunda bilinçlendirmek ve yaşadıkları sorunlarla etkili baş etmelerini sağlamak amacıyla hizmet içi eğitim, seminer gibi etkinliklerin düzenlenmesi önemlidir. Ayrıca hastalara yönelik, yaşadıkları sorunları kolaylıkla ifade edebilecekleri, benzer sorunlar yaşayan kişilerle bir arada olacakları grup çalışmalarının yapılmasının önemli olduğu düşünülmektedir.

\section{Kaynaklar}

1. Uzun Ş, Kara B, İşcan B. Hemodiyalize Giren Kronik Böbrek Yetmezliği Olan Hastalarda Uyku Sorunları. Türk Nefroloj, Diyaliz ve Transplantasyon Dergisi 2003;12(1): 61-66.

2. Tedeschi RG, Calhoun LG. Trauma and transformation: Growing in the aftermath of suffering. 3nd ed. Thousand Oaks, CA: Sage:1995.p. 60-117.

3. Tedeschi RG, Calhoun LG. The posttraumatic growth inventory: measuring the positive legacy of trauma. Journal of Traumatic Stress 1996;9(3): 455-71.

4. Linley PA, Joseph S. Positive change following trauma and adversity. Journal of Traumatic Stress 2004;17: 11-21.

5. Dürü Ç. Travma Sonrası Büyüme. Ufuk Üniversitesi Sosyal Bilimler Enstitüsü Dergisi 2014;6(1): 114-143.

6. Kaçmaz N. (2003). Fiziksel Hastalığa Uyum Güçlüğü Yaşayan Hastalarda Konsültasyon Liyezon Psikiyatrisi Hemşireliği Modeli Geliştirme Çalışması. Yayınlanmamış Doktora Tezi, İstanbul Üniversitesi Sağlık Bilimleri Enstitüsü.

7. Erdem N, Karabulutlu E, Okanlı A, Tan M. Hemodiyaliz Hastalarında Umutsuzluk ve Yaşam Doyumu. Uluslararası İnsan Bilimleri Dergisi 2004; ISSN: 1303-5134 www.insanbilimleri.com. (Erişim: 24.06.2011). 
8. Dadalı Z. (2009). Hemodiyaliz ve Prediyaliz Hastalarında Depresyon Ve Yaşam Kalitesinin Karşıllaştırılması. Yayınlanmamış Uzmanlık Tezi, T.C. Sağlık Bakanlığı Prof. Dr. Mazhar Osman Ruh Sağlığı ve Sinir Hastalıkları Eğitim ve Araştırma Hastanesi, 13. Psikiyatri Birimi İstanbul.

9. Mutlu E. (2007). Hemodiyaliz Hastalarının Sosyo-Demografik Özellikleri, Sosyal Destek Kaynakları Ve Hastalık Sürecinin Benlik Saygısına Etkisi. Yayınlanmamış yüksek lisans tezi, Hacettepe Üniversitesi Sosyal Bilimler Enstitüsü.

10. Zengin O, Yıldırım B. Hemodiyaliz Hastalarının Psikososyal Sorunlarına İlişkin Algıları. Türk Nefroloji, Diyaliz ve Transplantasyon Dergisi 2017;26(1): 67-73.

11. Yavuz D, Yavuz R, Altunoğlu A. Hemodiyaliz Hastalarında Görülen Psikiyatrik Hastalıklar. Türk Tıp Dergisi 2012;6(1): 33-36.

12. Zerach G, Solomon Z, Cohen A, Ein-Dor T. PTSD, resilience and posttraumatic growth among ex-prisoners of war and combat veterans. The Israel Journal of Psychiatry and Related Sciences 2013;50 (2): 91-116.

13. Yılmaz GA. (2014). Hemodiyaliz ve Periton Diyaliz Hastalarında Depresyon, Kaygı, Benlik Saygısı ve Sosyal Uyumun Değerlendirilmesi. Yayınlanmamış Uzmanlık Tezi, Uludağ Üniversitesi Tıp Fakültesi.

14. Cimilli C. Hemodiyalizin Psikiyatrik Yönleri. Türk Nefroloji Diyaliz ve Transplantasyon Dergisi 1994; 3(3): 88-92.

15. Özatalay S. (1990). Kronik Hemodiyaliz Programındaki Hastalarda Anksiyete. Yayınlanmamış Uzmanlık Tezi, Atatürk Üniversitesi Tıp Fakültesi.

16. Aydemir Ç, Cebeci S, Göka E, Kasım İ, Tüzer V. Kronik Böbrek Yetmezliği Hastalarının Yakınlarında Yaşam Kalitesi Ve Psikiyatrik Semptomlar. Kriz Dergisi 2002;10(2):29-39.

17. Tedeschi RG, Calhoun LG. Posttraumatic growth: conceptual foundations and empirical evidence. Psychological Inquiry 2004;15(1):1-18.

18. Calhoun LG, Tedeschi RG. Emotion Regulation and Posttraumatic Growth. Posttraumatic Growth İn Clinical Practice 1nd ed. New York: Routledge; 2013. p. 65-78.

19. Wortman CB. Posttraumatic growth: Progress and problems. Psychological Inquiry 2004;15(1): 81-90.

20. Frazier P, Conlon A, Glaser T. Positive and negative life changes following sexual assault. Journal of Consulting and Clinical Psychology 2001;69(6): 1048-1055.

21. Kılıç C. Ruhsal travma sonrası stres bozukluğu gelişiminin belirleyicileri. Aker T, Önder ME, eds. Psikolojik travma ve sonuçları. İstanbul: 5US; 2003.s. 51-63.

22. Sherr L, Nagra N, Kulubya G, Catalan J, Clucas C et al. HIV infection associated post-traumatic stress disorder and post-traumatic growth-a systematic review. Psychology, Health \& Medicine 2011;16 (5): 612-629.

23. Park CL, Chmielewski J, Blank TO. Post-traumatic growth: finding positive meaning in cancer survivorship moderates the impact of intrusive thoughts on adjustment in younger adults. Psycho-Oncology 2010;19 (11): 1139-1147.

24. Elçi Ö. (2004). Predictive values of social support, coping styles and stress level in posttraumatic growth and burnout levels among the parents of children with autism, Yayımlanmamış Yüksek Lisans Tezi, Orta Doğu Teknik Üniversitesi, Sosyal Bilimler Enstitüsü.

25. Hafstad GS, Kilmer RP, Gil-Rivas V. Posttraumatic growth among Norwegian children and adolescents exposed to the 2004 tsunami. Psychological Trauma: Theory, Research, Practice, and Policy 2011;3(2): 130-138.

26. Gerrish N, Dyck MJ, and Marsh A. Post-traumatic growth and bereavement. Mortality 2009;14(3): 226-244.

27. McElheran M, Briscoe-Smith A, Khaylis A, Westrup D, Hayward C, et al. Conceptual model of post-traumatic growth among children and adolescents in the aftermath of sexual abuse Counseling Psychology Quarterly 2012;25(1): 73-82.

28. Nuttman-Shwartz O, Dekel R, Tuval-Mashiach R. Post-traumatic stress and growth following forced relocation. British Journal of Social Work 2011;41(3): 486-501.

29. Cui C, Wang K, An J, Jin C. Current status and influencing factors of post-traumatic growth in maintenance hemodialysis. International Journal of Nursing Sciences 2017;4(2): 362-366.

30. Sadeghpour F, Heidarzedeh M, Naseri P, Mohammadi M. The relationship between emotional intelligence with posttraumatic growth in hemodialysis. Journal of Health and Care 2019;21(1): 7-15.

31. Kamran F. Transitions in Psychological Well-being and Life Orientation: The Phenomenon of Post Traumatic Growth after Renal Transplantation. Pakistan Journal of Psychological Research 2016; 31(2): 419-440.

32. Yorulmaz H, Bayraktar S, Özdilli K. Posttraumatic growth in chronic kidney failure disease. Procedia Social and Behavioral Sciences 2010;2(5): 2313-2319.

33. Joseph S, Linley PA. Positive adjustment to threatening events: An organismic valuing theory of growth through adversity. Review of general psychology 2005;9(3): 262-80.

34. Iş1khan V. Kanser ve Sosyal Destek. Toplum ve Sosyal Hizmet 2007;18: 15-29. 
35. Heaney CA, Israel BA. Social networks and social support. In: Health behavior and health education theory, research, and practice. Eds: Glanz K, Rımer B, VISWANATH K. 4th. ed. San Francisco: Jossey-Bass; 2008. p.169-188.

36. Kavak F, Mankan T, Polat H, Çıtlık Sarıtaş S, Sarıtaş S. Hemşirelerin manevi bakıma ilişkin görüşleri. İnönü Üniversitesi Sağlık Bilimleri Dergisi 2014;3(1): 21-24.

37. Patel SS, Peterson RA, Kimmel PL. The impact of social support on end stage renal disease. Seminars in Dialysis 2005;18 (2): 98-102.

38. Janet L, Joan K. Stressors, coping and depression in hemodialysis patients. Journal of Advanced Nursing 2001;32(2): 200-207.

39. Mok E, Tam B. Stressors and coping methods among chronic haemodialysis patients in Hong Kong. Journal of Clinal Nursing 2001;10(4): 503-11.

40. Hiçdurmaz D, Öz F. Hemodiyaliz ve Sürekli Ayaktan Periton Diyalizi Uygulanan Hastaların Stresle Başa Çıkma Biçimleri. Hacettepe Üniversitesi Sağlık Bilimleri Fakültesi Hemşirelik Dergisi 2009;16(3):1-16.

41. Özcan Y, Utaş C, Baştürk M, Aslan SS. Hemodiyaliz uygulanan hastalarda eritropoetin kullanımının depresyon, anksiyete ve yaşam kalitesi üzerine etkileri. Klinik Psikofarmakoloji Bülteni 2000;9(2): 109-111.

42. Kocaman N. Genel hastane uygulamasında psikososyal bakım ve konsültasyon liyezon psikiyatrisi hemşireliği. Cumhuriyet Üniversitesi Hemşirelik Yüksekokulu Dergisi 2005;9(1):49-54.

43. Oflaz F. Felaketlerin Psikolojik Etkileri ve Hemşirelik Uygulaması. Cumhuriyet Üniversitesi Hemşirelik Yüksekokulu Dergisi 2008;12(3): 70-76.

44. Towsend MC. Trauma-and Stressor-Releated Disorder Psychiatric Mental Health Nursing: Concepts of Care in Evidence-Based Practice 8nd ed. London: FA Davis Company: 2015. p. 559-78.

45. Boyd MA. Contemporary psychiatric nursing practice In: Kluwer W. ed. Psychiatric nursing contemporary practice. 5th ed. Philadelphia: Williams\&Wilkins; 2002. p. 177-92.

46. Kum N. Psikiyatri hemşireliği uygulama standartları. Kum N, eds. Psikiyatri Hemşireliği El Kitabı. 2. Baskı. İstanbul: Vehbi Koç Vakfı Yayınları; 1996. s. 4-8.

47. Çam O, Büyükbayram A, Turgut ÖE. Travma Sonrasında Ruh Sağlığı ve Hastalıkları Hemşireliği Yaklaşımı. Anadolu Hemşirelik ve Sağlık Bilimleri Dergisi 2016;19(3): 210-216.

48. Oflaz F, Özcan CT, Taştan S, Çiçek H, Aslan Ö ve ark. Hemşirelerin Travma Sonrası Stres Bozukluğu Belirtilerini Tanıma Durumları. Psikiyatri Hemşireliği Dergisi 2010;1(1):1-6. 